\title{
Frequency and Histopathological variants of Leiomyoma in Uterine Specimens in a Tertiary Care Hospital.
}

\author{
Tabbassam Naheed Kauser ${ }^{1}$, Abdul Ghafoor², Mohammad Sajjad ${ }^{3}$, Zubaida Khanum4, \\ Bushra Nabi ${ }^{4}$, Hina Khan ${ }^{4}$
}

\begin{abstract}
Background: Leiomyoma is the commonest benign smooth muscle tumor of uterus. It also occur in other organs like gall bladder, skin, gasterointestinal tract etc. Leiomyosarcoma is a rare malignant counter part of leiomyoma.

Objective: To see the frequency of histopathological variants of leiomyomas in uterine specimens in Southern District of Khyber Pakhtunkhwa Pakistan.

Material and Methods: This descriptive study was conducted in Department of Pathology, Bannu Medical College Bannu in collaboration with Government and Private Hospitals of the Southern District of KPK. The duration of study was seven years from January 2011 to December 2017. A total of 210 specimen of leiomyoma were included in this study. Inclusion criteria was all biopsies of uterine leiomyomas of any age. Exclusion criteria wa autolysed and insufficient biopsy specimen. All biopsies were fixed over night in $10 \%$ buffered formalin, processed for histopathological slides preparation. Finally slides were prepared, labeled and reported by Histopathologist. . All the data was analysed in Statistical Package for Social Sciences (SPSS) version 20 for frequency with percentages and mean with standard deviation.

Results: In this study of 210 le iomyoma cases, the age range was from $25-65$ years. The commonest age group was $36-45$ years followed by $25-35$ years. The frequency of leiomyoma was $21.5 \%$ amongst the total uterine biopsy specimen. Histologically the usual leiomyoma was comprising of $176(83.80 \%)$ followed by hyalinised leiomyoma $11(5.23 \%)$, myxoid leiomyoma 09(4.28\%), lipoleiomyoma $05(2.38 \%)$, cellular leiomyoma $04(1.90 \%)$, shwannian leiomyoma $03(1.42 \%)$ and one each of symplastic and angioleiomyoma $01(0.47 \%)$.

Conclusin: Leiomyoma which is the commonest benign smooth muscle tumor of uterus have a number of histological variants. In this study usuall leiomyoma was the commonest variant followed by hyalinized leiomyoma, myxoid leiomyoma and lipoleiomyoma. It is important to separate various types of leiomyoma on histology to avoid confusion of misdiagnosis.

Key Wordss: Histopathology. Fibroids. Leiomyoma variants. Hysterectomy. Myomectomy.
\end{abstract}

This article may be cited as: Kauser TN, Ghafoor A, Sajjad M, Khanum Z, Nabi B, Khan H. Frequency and Histopathological variants of Leiomyoma in Uterine Specimens in a Tertiary Care Hospital. J Saidu Med Coll Swat 2021;11(1):09-13

\section{INTRODUCTION}

Leiomyoma is the commonest benign tumor of the uterus, usually no clinical symptoms are there when small, when large may causes abnormal uterine bleeding, pressure sensation in perineum, lower abdominal pain and sometimes associated with missed abortion or infertility. ${ }^{1}$

The exact aetiology of leiomyoma is not known, these are considered as monoclonal tumors and runs in families with approximately 40 to $50 \%$ reveals karyotypic abnormalities. ${ }^{2}$

Leiomyoma typically occurs during the reproductive years of ages. An average about $50 \%$ of women develop uterine leiomyomas by the age of 50 years. They are clinically noted in $20-$ $30 \%$ of women over the age of 30 years. In 2013 it

1.Department of Gyne \& Obs, Swat Medical College, Swat

2.Surgery Deptt. Khalifa Gul Nawaz Teaching Hospital Bannu.

3.Pathology Deptt. Bannu Medical College Bannu.

4.Gyne \& Obstetrics Deptt. Khalifa Gul Nawaz Teaching Hospital Bannu.

Correspondence: Dr. Mohammad Sajjad

Pathology Deptt. Bannu Medical College Bannu KPK. Pakistan.

Email Adress: sajjadkhattak66@gmail.com

Phone No. 0333-9343645 was estimated that about 171 million of women were suffering from uterine leiomyoma. ${ }^{3,4}$

Leiomyoma is one of the common cause of gynaecological surgery in form of hysterectomy or myomectomy worldwide. The reason for hysterectomy and myomectomy is clinical symptomatology which the patient suffers in their clinical course.

Leiomyomas of uterus are commonly located intramurally (within the myometrium) followed by subserosal (perimetrium)and submucosal location (beneath the endometrium). Also liomyoma can occure in broad ligament, separate from uterus as well in the vicinity of uterus. ${ }^{6}$

There are different histological variants of leiomyomas. These are usual leiomyoma, cellular leiomyoma, epithelioid leiomyoma, myxoid leiomyoma, angioleiomyoma, lipoleiomyoma, atypical/symplastic leiomyoma etc. Grossly leiomyomas are well circumscribed solid, firm tumors usually solitary or may be multiple in $2 / 3^{\text {rd }}$ cases. $^{7}$ Microscopically usual leiomyoma is composed of whorl anastomosing fasicles of 
uniform smooth muscles cells, cellular leiomyoma is more cellular as compared to usual leiomyoma, ep ithelioid le io my oma is composed of predominantly sheets of epithelial like muscles fibers, myxoid leiomyoma have myxoid background with interspersed smooth muscle cells, angioleiomyoma contain predominant blood vessels in background, lipoleiomyoma contain entrapped foci of adipocytes in between where as atypical/symplastic leiomyoma contain scattered large cells with ancient changes. ${ }^{8}$ The objective of this study was to see the frequency histopathological variants of uterine leiomyoma in the southern districts of KPK. Pakistan.

\section{MATERIALS AND METHODS}

This descriptive study was conducted in Department of Pathology, Bannu Medical College Bannu in collaboration of Government and Private Hospitals of the Southern Districts Bannu, Karak, Lakki Marwat, FR Bannu etc. The biopsies were carried out and reported in a private Shah Noor laboratory at Bannu by a qualified Histopathologist. The duration of study was seven years from January 2011 to December 2017. A total of 210 specimen of leiomyoma were included in this study. Inclusion criteria was all biopsies of uterine leiomyomas from hysterectomy or myomectomy specimen of any age. Exclusion criteria was autolysed and insufficient biopsy specimen. All biopsies were fixed over night in $10 \%$ buffered formalin, processed for histopathological slides preparation. Finally slides were prepared, labeled and reported by Histopathologist.
All biopsies were collected with relevant clinical information, registered, labeled and fixed in $10 \%$ buffered formalin overnight. Next day gross performed, sections taken, processed in various concentrations of ethonal, xylol, solid paraffin wax. Blocks prepared freezed in refrigerator, 5 micron thin microtome sections taken, slides prepared, and processed for Hematoxylin and Eosin staining. Lastly slides mounted with DPX and reported by Histopathologist. All the data was analysed in Statistical Package for Social Sciences (SPSS) version 20 for frequency with percentages and mean with standard deviation.

\section{RESULTS}

In this study of 210 leiomyoma the age range was from 25-60 years with mean age of $37.55 \pm 12.8$ years. The frequency of leiomyoma was $21.5 \%$ amongst total uterine biopsy specimen. The number of total uterine biopsies were 974 amongst which 210 were leiomyoma. On gross examination intramural leiomyomas were 136 $(64.76 \%)$ followed by subserosal leiomyomas 59 $(28.09 \%), 12(5.71 \%)$ and broad ligament leiomyoma $03(1.42 \%)$. Histologically the usual leiomyoma was comprising of $176(83.80 \%)$ followed by hyalinised leiomyoma 11 (5.23\%), myxoid leiomyoma 09(4.28\%), lipoleiomyoma 05 $(2.38 \%)$, cellular leiomyoma $04(1.90 \%)$, shwannian leiomyoma $03(1.42 \%)$ and one each of symplastic and angioleiomyoma leiomyoma 01 $(0.47 \%)$.

Table 1. Different age groups distribution of uterine leiomyomas ( $n=210)$.

\begin{tabular}{|c|c|c|}
\hline Age group in years & Number of cases & Percentage \\
\hline $25-35$ & 57 & $27.14 \%$ \\
\hline $36-45$ & 104 & $49.52 \%$ \\
\hline $46-55$ & 42 & $20.00 \%$ \\
\hline$>55$ & 07 & $3.33 \%$ \\
\hline Total & 210 & $100 \%$ \\
\hline
\end{tabular}

Table 2. Histological variants of uterine leiomyomas $(n=210)$.

\begin{tabular}{|c|c|c|}
\hline Type of liomyoma & Number of cases & Percentages \\
\hline Usual leiomyoma & 176 & $83.80 \%$ \\
\hline Hyaline liomyoma & 11 & $5.23 \%$ \\
\hline Myxoid leiomyoma & 09 & $4.28 \%$ \\
\hline Liopleiomyoma & 5 & $2.38 \%$ \\
\hline Cellular leiomyoma & 4 & $1.90 \%$ \\
\hline Schawnnian leiomyoma & 3 & $1.42 \%$ \\
\hline Symplastic leiomyoma & 1 & $0.47 \%$ \\
\hline Angioleiomyoma & 1 & $0.47 \%$ \\
\hline
\end{tabular}




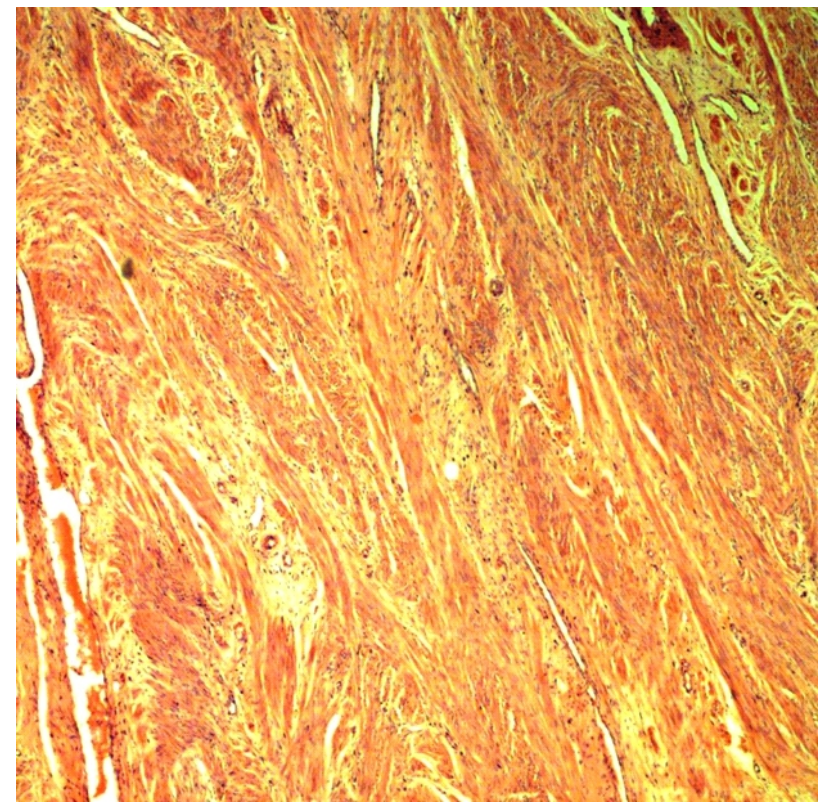

Figure: I. Usual leiomyoma. 4x10 view.

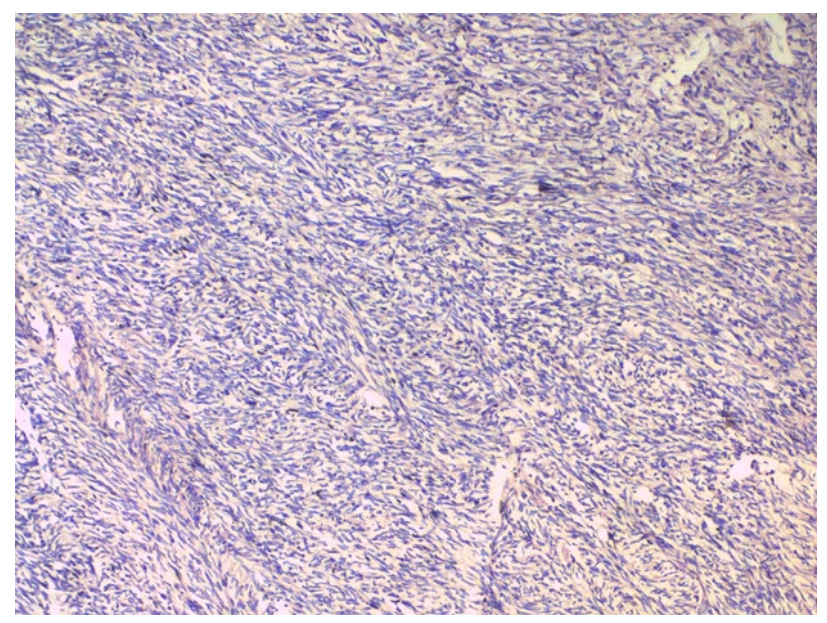

Figure: II. Cellular leiomyoma. 4x10 view.

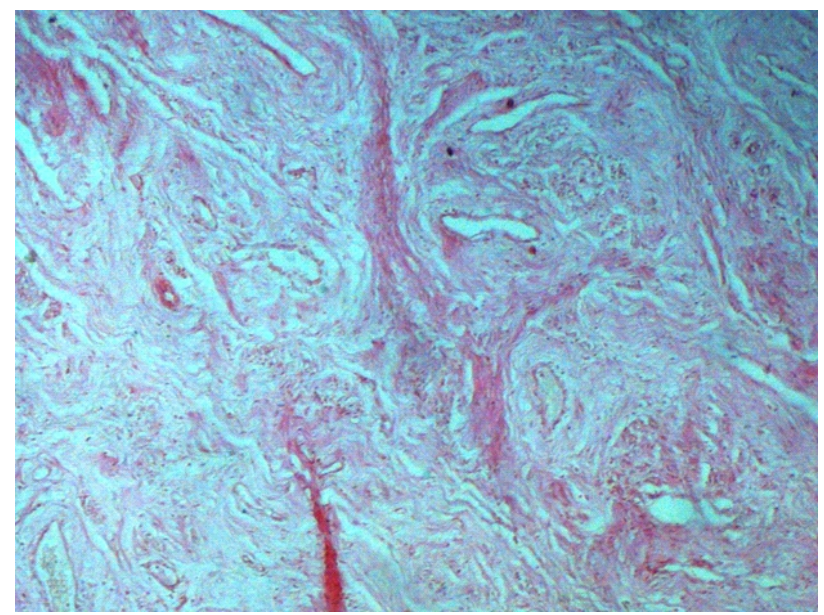

Figure: III. Angioleiomyma. 4x10 view.

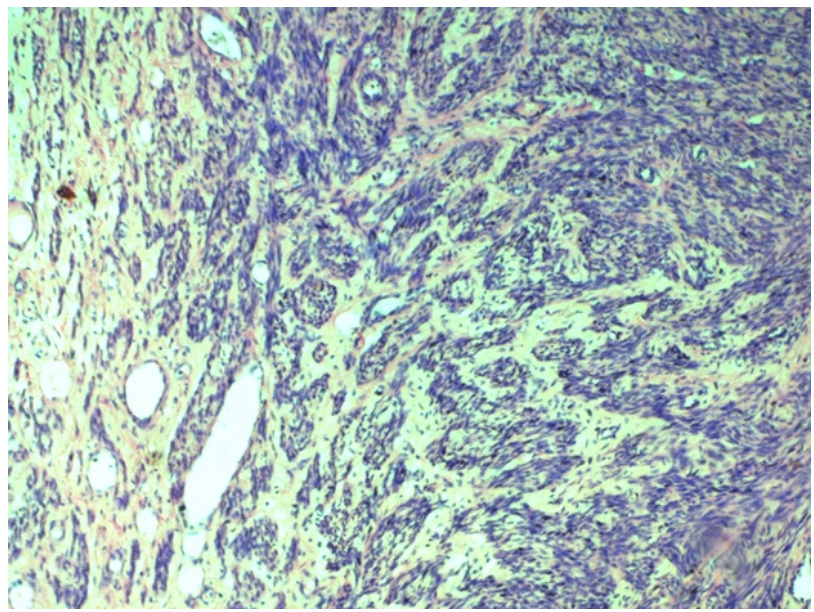

Figure: IV. Schwannian leiomyoma. 10x10 view.

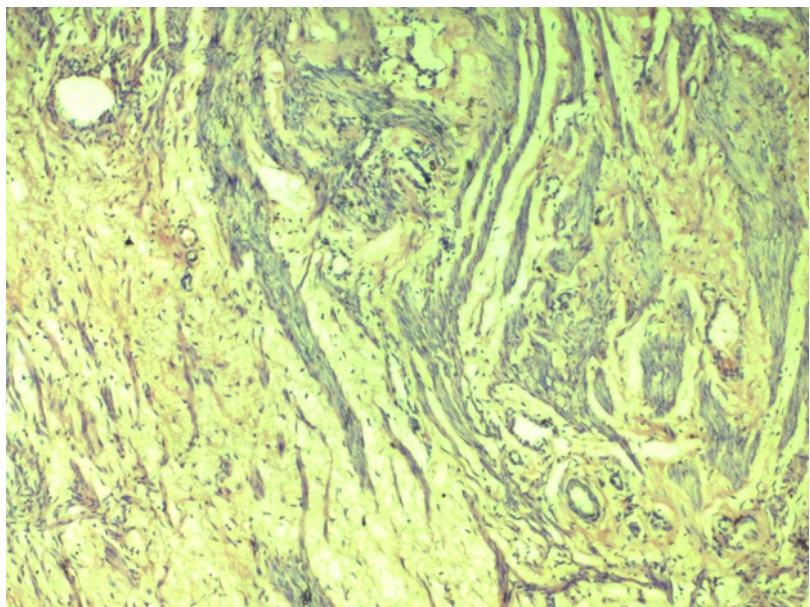

Figure: V. Hyalinized leiomyoma.10x10 view.

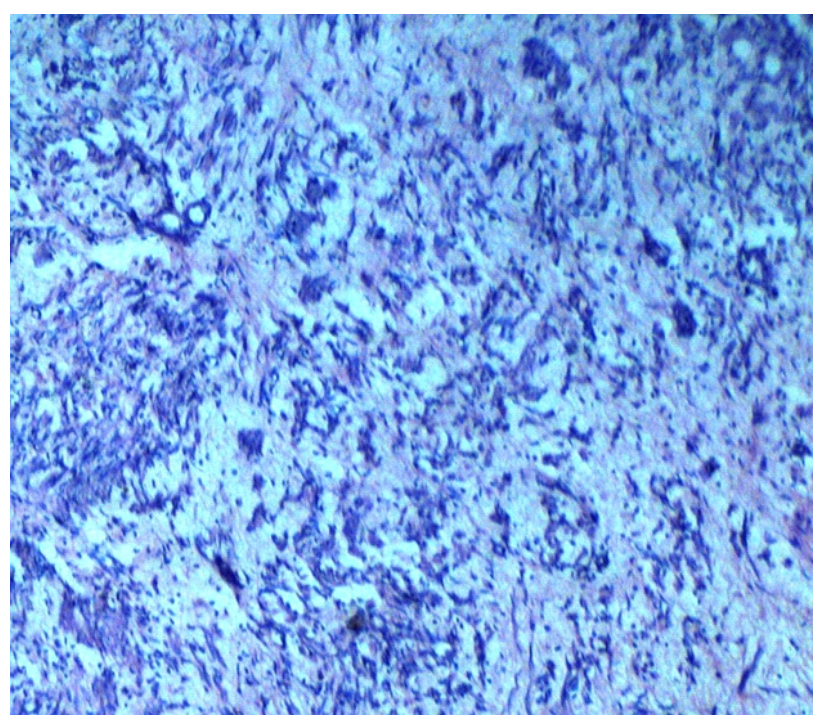

Figure: VI. Myxoid leiomyoma. 10X10 view. 


\section{DISCUSSION}

Leiomyoma also called fibroid or myoma are common uterine neoplasm occurring in $20-25 \%$ in women of reproductive age. Although benign, may cause problem like menorrhagia, dysmenorrheal, infertility etc. They may need hormone for their growth and maintenance as they have increased estrogen receptors than normal uterine myometrium. Leiomyoma may undergo secondary changes, such as hyalinization, calcification as well as myxoid changes. ${ }^{9}$

In this study the age range was from 25-60 years with mean age of $37.55 \pm 12.8$ years. In a study conducted by Abraham et $\mathrm{al}^{10}$ in India in 2013 the age range was from 20-72 years. Other studies conducted by Lahori ${ }^{11}$ and Gowri et $\mathrm{al}^{12}$ in India in 2016 and 2013 the age range was from 18-62 years and $25-59$ years respectively.

In this study the majority of the patients were in the age group of $36-45$ years $49.52 \%$ followed by $26-$ 35 years $27.14 \%$, $46-55$ years $20.00 \%$ and above 55 years $3.33 \%$. In a study conducted by Abraham et $\mathrm{al}^{10}$ the common age group was from 41-50 years $46.5 \%$. Other studies conducted by lahori ${ }^{11}$ and Gowri et $\mathrm{al}^{12}$ in 2016 and 2013 the common age groups were $41-50$ years $46.84 \%$ and $49 \%$ respectively.

In this study the frequency of leiomyoma was $21.5 \%$. Other studies conducted by Zaid et $\mathrm{al}^{13}$, Adelusola et $\mathrm{al}^{14}$, Talukdar et $\mathrm{al}^{15}$ and Borgfeldt et $\mathrm{al}^{16}$, show frequency of leiomyoma $26 \%, 17 \%$, $13 \%$ and $8 \%$ respectively. These studies show their frequencies near to this study, where as other studies conducted by Pitty et $\mathrm{al}^{17}$, Naheed et $\mathrm{al}^{18}$ and Sobande et $\mathrm{al}^{19}$ show frequencies of leiomyomas as $36 \%, 40 \%$ and $48 \%$ respectively, which are slightly higher than this study.

In this study intramural leiomyomas were 136 $(64.76 \%)$ followed by subserosal leiomyomas 59 (28.09\%), submucosal leiomyoma 12 (5.71\%) and leiomyoma of broad ligament were 03 $(1.42 \%)$.

In a study conducted by Lahori et $\mathrm{al}^{11}$ intramural leiomyomas were $56.86 \%$ followed by subserosal leiomyomas $31.37 \%$, submucosal leiomyoma $8.83 \%$ ) and leiomyoma of broad ligament were $2.94 \%$ ). Another study conducted by Gowri et $\mathrm{al}^{12}$ intramural leiomyomas were $48 \%$ followed by subserosal leiomyomas $16 \%$, submucosal leiomyoma $03 \%$ ) and leiomyoma of other locations were $33 \%$. Another study conducted by Priyadarshini et $\mathrm{al}^{20}$ in 2018 in India the intramural leiomyomas were $67 \%$ followed by subserosal leiomyomas $20 \%$, submucosal leiomyoma $11 \%$ ) and leiomyoma of broad ligament were $2 \%$.

In this study usual leiomyomas was $83.80 \%$ followed by hyalinised leiomyoma $5.23 \%$, myxoid leiomyoma $4.28 \%$, lipoleiomyoma $2.38 \%$, cellular leiomyoma $1.90 \%$, shwannian leiomyoma $1.42 \%$ and both symplastic and angioleiomyoma leiomyoma as $0.47 \%$.

In a study conducted by Lahori et $\mathrm{al}^{11}$ the usual leiomyoma was $53.16 \%$ followed by hyalinised leiomyoma $6.33 \%$, myxoid leiomyoma $3.8 \%$, cellular leiomyoma $6.3 \%$, angioleiomyoma 3.8\%. Another study conducted by Kokila et $\mathrm{al}^{21}$ in 2017 in India the usual leiomyoma was $88.6 \%$ followed by Hyalinized leiomyoma $6.34 \%$, cellular leiomyoma $0.48 \%$ symplastic leiomyoma $0.28 \%$ and shwannian leiomyoma $0.142 \%$. Another study conducted by Manjula et $\mathrm{al}^{22}$ in 2011 usual leiomyoma was $95.45 \%$, lipoleiomyoma $2.05 \%$, myxoid leiomyoma $0.45 \%$, cellular leiomyoma $0.45 \%$ and shwannian and symplastice leiomyoma as $0.22 \%$.

\section{CONCLUSION}

Leiomyoma which is the commonest benign smooth muscle tumor of uterus have a number of histological variants. In this study usuall leiomyoma was the commonest variant followed by hyalinized leiomyoma, myxoid leiomyoma, lipoleiomyoma etc. It is important to separate various types of leiomyoma on histology to avoid confusion of misgiagnosis.

\section{REFERENCES}

1. Kumar $\bigvee, A b b a s s A K$, Aster CJ. Inflammation healing and repair. In: Robin's pathological basis of diseases. $9^{\text {th }}$ ed.Philadelphia:WB Saunders,2013; 1030-39.

2. Rosai J. Akerman. Female Genital Tract. In: Rosai and Ackerman's Surgical Pathology. $9^{\text {th }}$ edn. St.Louis: Elsevier Mosby, 2004:1718-27.

3. Gupta G, Kotasthane D, Kotasthane V. Hysterectomy: a clinico-pathological correlation of 500 cases. The Internet Journal of Gynecology and Obstetrics. 2009;14(1): 147-53.

4. Karthikeyan TM, Veenaa NN, Ajeeth Kumar CR, Thomas E. Clinico-pathological study of hysterectomy among rural patients in a tertiary care center. IOSR Journal of Dental and Medical Sciences. 2015;14(5):25-7. 
5. Rani S. V. R, Thomas S. Leiomyoma, a major cause of abnormal uterine bleeding. $J$ of Evolution of Medical and Dental Sciences.2013;2:2626-30.

6. Rather GR, Gupta Y, Bharadwaj S. Patterns of lesions in hysterectomy specimens; A Prospective study. J.K.Science 2013; 15(2)63-68.

7. Rizvi G, Pandey H, Pant H, Chufal SS, Pant P. Histopathological correlation of adenomyosis and leiomyoma in hysterectomy specimens as the cause of abnormal bleeding in women in different age groups in the kumaon region-A retrospective study. $\mathrm{J}$ of Midlife health.2013;4:27-30.

8. Sarfraz R, Sarfraz MA, Kamal F, Afsar A. Pattern of benign morphological myometrial lesions in total abdominal hysterectomy specimens. Biomedica. 2010;26:140-3.

9. Vaidya S, Vaidya SA. Patterns of lesions in hysterectomy specimens in a tertiary care hospital. J Nepal Med Assoc. 2015;53(197):18-23.

10. Abraham J, Saldanha P. Morphological variants and secondary changes in uterine leiomyoma- Is it important to recognize them? IJBMR 2013;4(12):639-45.

11. Lahori M, Malhotra SA, Sakul, Khajuria A, Goswami $\mathrm{KC}$. Clinicopathological spectrum of uterine leiomyomas in a state of Northern India: A Hospital based study. Int J Reprod Contracept Obstet Gynecol.2016;5(7):2295-99

12. Gowri M, Mala G, Murthy S, Nayak V. Clinicopathological study of uterine leiomyomas in Hysterectomy specimens. Journal of Evolution of Medical and Dental Sciences.2013;2(46): 9002-08.

13. Zaid SMO, Thabet MAB. Histopathological findings in Hysterectomy Specimen ; A retrospective study. Middle east Journal of Internal Medicine.2017;10(1):12-24.

14. Adelusola KA, Ogunniyi SO. Hysterectomies in Nigerians: histopathological analysis of cases seen in lle-Ife . Niger Post grad Med J. 2001 ; 8(1): 37-40.

15. Talukder SI, Haque MA, Huq MH, Alam MO, Roushan A, Noor Z. Histopathological analysis of hysterectomy specimens, Mymensingh J. 2007; 16: 18-24.

16. Borgfeldt $\mathrm{C}$, Andolf E. Transvaginal ultrasonographic findings in the uterus and the endometrium: Low prevalence of leiomyoma in a random sample of women age 25-40 years. Acta Obstet Gynecol Scand. 2000;79:202-7.

17. Pity IS, Jalal JA, Hassawi BA. Hysterectomy: A Clinicopathologic Study. Tikrit Medical J. 2011; 17(2): 7-16.

18. Naheed K, Hussain A, Ali R. Clicico- Pathological study of hysterectomy at Pak Red Crescent Medical and Dental College. JIIMC.2018;13(2):62-5.

19. Sobande AA, Eskander M, Archibong EI, Damole IO. Elective hysterectomy: A Clinicopathological review from Abha Catchment Area of SaudiArabia. West Afr J Med. 2005; 24 (1): 31-35

20. Priyadarshini P, Gomathy E. Clinicopathological study of uterine leiomyomas in hysterectomy specimens; A retrospective study.2018; Int.J. Res. 6(2):571-6.

21. Kokila K, Rajavelu I. Histomorphological spectrum of uterine leiomyoma variants- One year retrospective study in a tertiary care centre.Int. J.Adv.Res.2017;5(5):2201-10.

22. Manjula K, Rao S, CHANDARSHAKER hr. Varients of leiomyoma; Histo morphological study of tumors of myometrium. Journal of South Asian Federation of Obstetric and Gynecology. 2011;3(2):89-92.
DATA SHARING STATEMENT: The data that support the findings of this study are available on request from the corresponding author. The data are not publicly available due to privacy or ethical restrictions.

CONFLICT OF INTEREST: Authors declare no conflict of interest.

GRANTED SUPPORT AND FINANCIAL DISCLOSURE:
Nil

\section{AUTHOR'S CONTRIBUTION}

Following authors have made substantial contributions to the manuscript as under

Kausar TN: $\quad$ Concept and design of study, Collection of data, statistical analysis

Ghafoor A, Sajjad M:Writing of manuscript, critical review of manuscript

Khanum Z: Analysis and interpretation of data, statistical analysis

Nabi B, Khan H: Data collection, bibliography

Authors agree to be accountable for all aspects of the work in ensuring that questions related to the accuracy or integrity of any part of the work are appropriately investigated and resolved. 